\title{
Drug pricing in South Korea
}

Hye-Young Kwon ${ }^{1}$, Brian Godman²,3

Mokwon University, Daejeon, South Korea

2Department of Laboratory Medicine, Division of Clinical Pharmacology, Karolinska Institutet, Karolinska University Hospital Huddinge,SE-141 86 Stockholm, Sweden

${ }^{3}$ Strathclyde Institute for Pharmacy \& Biomedical Sciences, University of Strathclyde, Glasgow, UK

(Accepted for publication - Applied Health Economics and Health Policy)

\begin{abstract}
Background: Between 2000 and 2013, spending on medicines in Korea increased by $275.3 \%$. In order to curb this trend, several pricing policies and measures were introduced. Objectives: This study reviews these policies and their implications. Methods: Review of pricing regulations as well as a literature review. Results: New medicines must now undergo both a reimbursement assessment and price negotiations. The reimbursement of new medicines is based on their cost-effectiveness. The prices of new medicines are subsequently fixed through negotiations between the payer, the National Health Insurance Service, and the relevant manufacturer. Generic drugs are automatically priced via a new standard methodology. Re-pricing mechanisms were complicated and now redundant. Conclusions: Simple and efficient measures rather than complex and inefficient measures are needed to maintain the value for money principle for new medicines as well as achieve financial efficiency through price competition among multiple s sourced drugs, building on the experiences in other countries.
\end{abstract}

\section{Key points for decision makers}

- Price regulations are necessary for the sustainability of health insurance plans in Korea. Various pricing mechanisms are being applied in accordance with the types of medicines.

- The positive listing based on cost-effectiveness appraisals and price negotiations has been implemented for new medicines since 2007. Repricing mechanisms including price-volume agreement, price cuts and delisting are now in place.

- Simple and efficient measures rather than complex and measures which can be problematic are needed to maintain the value for money principles as well as to achieve financial efficiency. This include pricing competition among generic drugs as well as additional initiatives to enhance their use

\section{Introduction and Aims}

Drug expenditure increased in Korea by $275.3 \%$ between 2000 and 2013 , when several policies were implemented In order to curb this increasing trend in pharmaceutical spending. This included th separation of dispensing from prescribing,

Other initiatives in recent years included the Drug Expenditure Rationalization Plan (DERP), announced in December 29, 2006, and coming into effect in 2007. The two main pillars of the DERP were the positive list system (PLS), developed via cost-effectiveness appraisals, and the price negotiation procedure between the payer, the National Health Insurance Service (NHIS), and pharmaceutical manufacturers [2]. 
Figure 1. Trend of drug spending

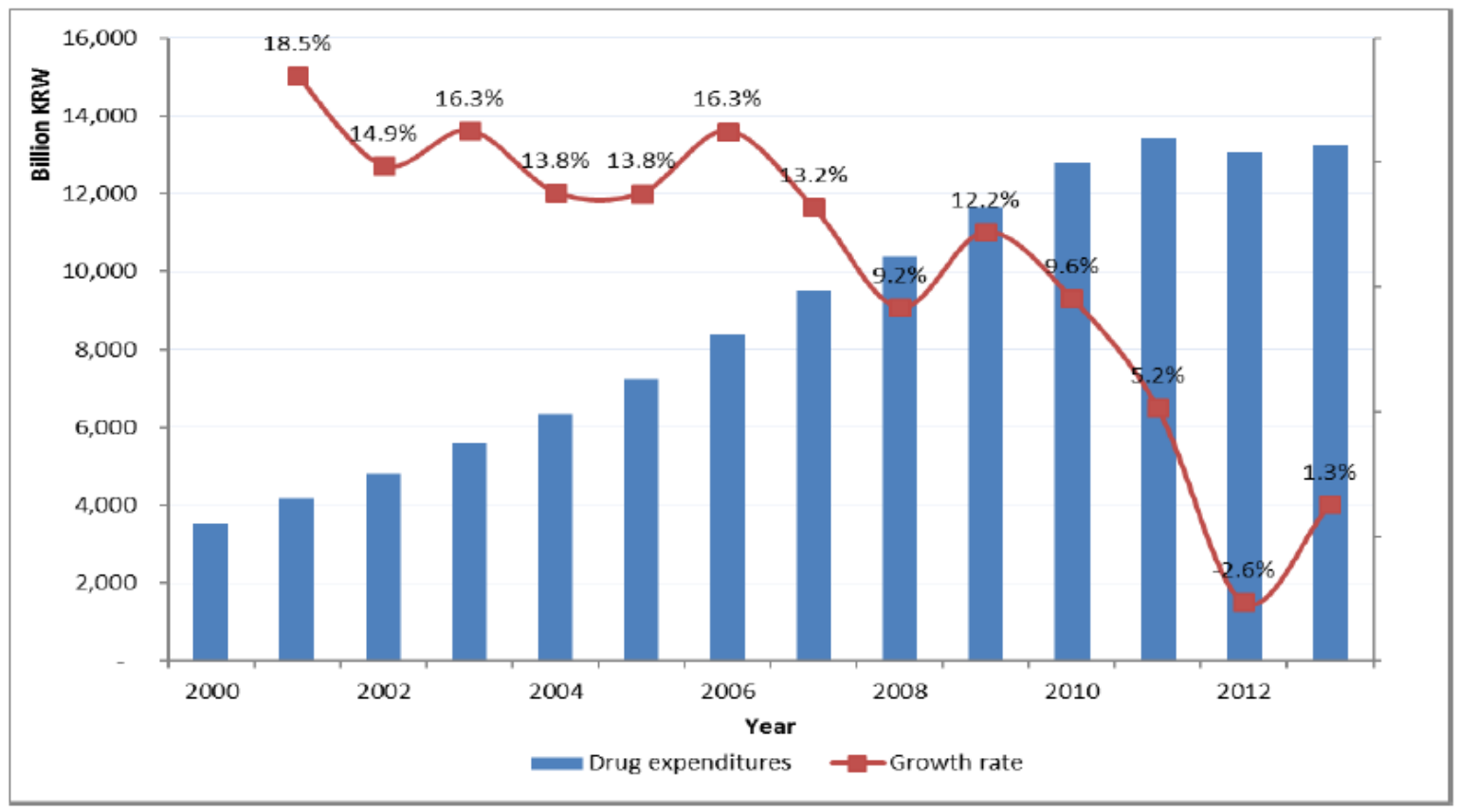

Note: 1 USD = Korean Won(KRW) 1,124 as of July 2016

The PLS is characterized as a selective listing of medicines with the aim of obtaining value for money in drug expenditure. Consequently, it emphasizes the importance of cost-effectiveness in addition to clinical effectiveness. The second pillar, price negotiation, is a new procedure in drug pricing that is independently executed from listing decisions.

In April 2012, a new drug pricing policy for off-patent drugs was introduced. This policy set the reimbursement price for outpatient drugs in order to strengthen market competition. The effect of these policies in terms of price competition among outpatient drugs is still questionable [3]. However, drug expenditure reduced in 2012 compared to 2011 although slightly increased in 2013 albeit at a lower rate than before as shown in Figure 1. Existing drug pricing policies though have now become complicated because numerous measures are now being applied.

Consequently, the aim of this study is to appraise current pricing policies for medicines in South Korea through an examination of pricing regulations and a literature review. This is not a systematic review. However, the opinions and the comments made are based on the considerable knowledge of the co-authors regarding the situation in South Korea combined with publications in this area, including publications of the co-authors. It is hoped these comments will stimulate debates in this important area to among relevant authorities in South Korea to improve the current situation, benefitting all key stakeholders in the future.

\section{Korean Pharmaceutical Benefit Scheme}

The Korean National Health Insurance (NHI) was introduced in 1977 and achieved almost universal health coverage by 1989 [4]. It is a mandatory insurance in which $97 \%$ of the total population is enrolled. While population coverage is close to $100 \%$, service coverage as of 2010 was only $58.7 \%$, which is lower than the OECD average $(73.1 \%)$. However, the benefit coverage for pharmaceuticals is $59.3 \%$, which is similar to OECD countries' average of $60.3 \%[5]$.

In 2006, expenditure on medicines in South Korea was $29.4 \%$ of total healthcare expenditure; consequently, a significant proportion of overall expenditure justifying increasing scrutiny. After 2007, numerous policy reforms regarding medicine prices were instigated, with spending on pharmaceutical expenditure decreasing to $26.1 \%$ of total healthcare expenditure in 2013 . However, this is still high compared to the average of OECD countries at $16.9 \%$ [6], necessitating additional measures for the future sustainability of the Korean healthcare system. 
As of January 1, 2014, 15,734 medicines have been registered in South Korea under the NHI. Drug spending in 2013, via claims data, was Korean Won (KRW) 13.2 trillion (USD 11,744 million, $\mathrm{USD} / \mathrm{KRW}=1,124$ as of July 2016) comprising, as mentioned, $26.1 \%$ of the total health expenditure. Expenditure for outpatient prescriptions was approximately $68.7 \%$ of the total pharmaceutical expenditure, with the remaining medicines used in hospitals [1]. There are several types of medicines available in Korea including new medicines, generic medicines, and line extensions. These will now be described in more detail, with comparisons with other countries where pertinent including generic prices in Europe. The price of medicines is regulated by the government under the NHI.. The costs of prescribed drugs are compensated by the NHIS, with patient co-payment for prescribed drugs approximately $30 \%$. The price regulation for medicines is currently managed by the Health Insurance Review and Assessment (HIRA) agency and the NHIS, and final approvals are made by the Ministry of Health and Welfare (MOHW).

\section{Drug pricing in South Korea}

Different measures regarding drug pricing in South Korea are currently applicable depending on the types of medicine. Table 1 shows an overview of the pricing mechanisms for each type of medicine.

Table 1. Pricing measures by the type of medicine

\begin{tabular}{|c|c|c|}
\hline Type of medicine & $\begin{array}{c}\text { Reimbursement } \\
\text { decision }\end{array}$ & Price fixing/Price cuts \\
\hline New drugs (NMEs) & $\begin{array}{l}\text { CE measures } \\
\text { (HIRA) }\end{array}$ & $\begin{array}{l}\text { Price negotiation } \\
\text { (NHIS) }\end{array}$ \\
\hline Generic medicines & $=$ & EMP: $53.5 \%$ of the originator medicine \\
\hline Line extensions & - & $\begin{array}{l}\text { Calculated by a formula proportional to } \\
\text { content }\end{array}$ \\
\hline $\begin{array}{l}\text { Drugs already listed } \\
\text { (HIRA) }\end{array}$ & $\begin{array}{l}\text { 1) Delisting } \\
\text { 2) Drug list } \\
\text { rearrangement } \\
\text { 3) Delisting when } \\
\text { illegal rebates } \\
\text { are detected, } \\
\text { such as a } \\
\text { penalty for } \\
\text { rebate giving- }\end{array}$ & $\begin{array}{l}\text { 4) Actual transaction pricing } \\
\text { (ATP) } \\
\text { - List price downward adjusted } \\
\text { toward actually transacted } \\
\text { prices when ATPs are } \\
\text { detected somehow } \\
\text { 5) Price cut by } 53.55 \% \text { after the } \\
\text { end of a patent } \\
\text { 6) Price-volume agreement (PVA) }\end{array}$ \\
\hline & $\begin{array}{l}\text { taking: dual } \\
\text { punishment } \\
\text { legislation }\end{array}$ & $\begin{array}{l}\text { 7) Appeal of price rise by } \\
\text { manufacturers }\end{array}$ \\
\hline
\end{tabular}

NMEs: new molecular entities; CE: cost effectiveness; HIRA: Health Insurance Review and Assessment Service; NHIS: National Health Insurance Service; EMP: Equal medicine pricing

\section{New drug pricing}

New drugs (NMEs) now have to undergo two independent procedures for their listing and pricing [Figure 2]. According to the DERP, these procedures are HIRA's decision-making on reimbursements and NHIS' pricing negotiations. First, HIRA evaluates the potential reimbursement of new drugs considering several factors. These include cost-effectiveness, clinical usefulness and budget impact. Until 2007, almost all medicines that received market approval from the Ministry of Food and Drug Safety had been listed as reimbursed medicines within the NHI with little consideration for budget impacts and/or cost-effectiveness [7].

Since the PLS implementation, 491 items were targeted for economic evaluation. 331 items (205 substances), which accounted for $67.4 \%$ of the items, were approved on the basis of their cost effectiveness and were reimbursed as of December 31,2013. $27.7 \%$ were not reimbursed, and the remaining $4.9 \%$ are still under assessment and awaiting decisions [1]. 
Figure 2. Drug reimbursement review and pricing in Korea
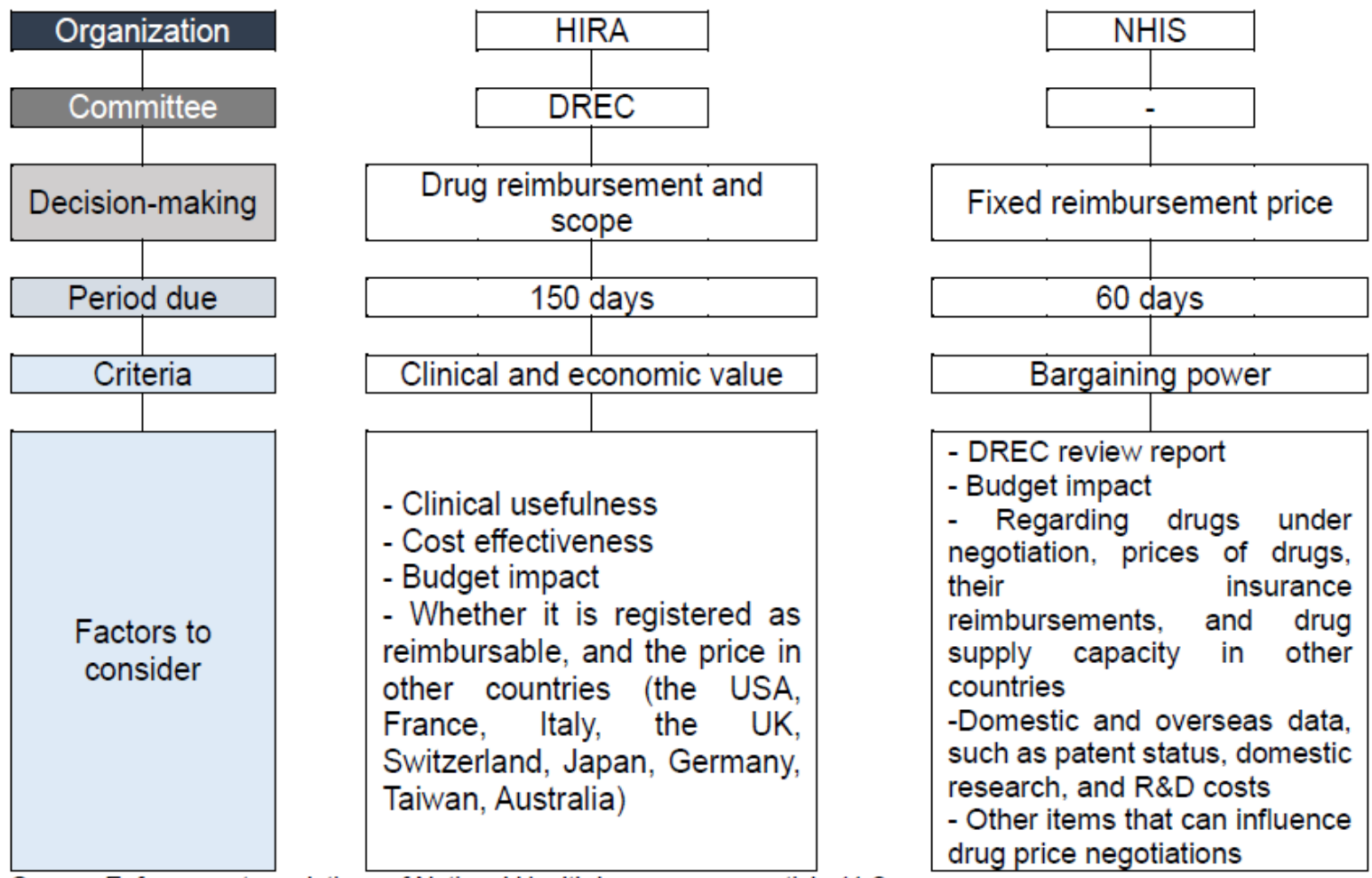

Source: Enforcement regulations of National Health Insurance raw article 11-2

Abbreviation: HIRA: Health insurance review and assessment service; NHIS: National health insurance service; DREC:

Drug reimbursement and evaluation committee

After HIRA's decisions regarding reimbursements, medicines designated as potentially reimbursed require 60 days for face-to-face negotiation between the NHIS and the drug manufacturers in order to decide on their prices and the expected budget impact based on their anticipated utilization. During drug pricing negotiations, the NHIS considers the prices in OECD countries, Taiwan, Singapore, as well as the prices of substitute medicines in the same class or related class. In this process, the highest price that the NHIS can agree to is the price of medicines that the DREC has approved as cost-effective, and justifications for lowering drug prices are sought based on substitute drug prices or prices in countries outside of Korea. If the price negotiation fails, the medicine cannot be listed. Under these circumstances, the new medicine must go through HIRA's registration process again [8].

Agreement on the expected volume of the new medicine is required for application at the agreed price in order to minimize the financial risk from introducing the new medicine.

As a result, if the actual consumed volume of the new drug exceeds $30 \%$ of the expected volume after a year, the drug price must be renegotiated (Price Volume Agreements - PVAs. Discussed in more detail below). PVAs are common among a number of European countries, especially where there are limited demand-side measures to regulate physician prescribing habits $[9,10]$.

A total of 259 items were registered through drug price negotiations between 2007 and 2013. This constitutes $78.2 \%$ (259) of the 331 items that were approved for reimbursement by HIRA [1]. According to Kim et al., the average price negotiation was $86.9 \%$ (standard deviation $11.7 \%$ ) of the agreed HIRA price. Consequently, drug price negotiations decreased the prices of new medicines by approximately $13.1 \%$ from the price approved for reimbursement by HIRA [11]. Consequently, can be considered successful.

\section{Pricing of generic medicines}

Generic medicines are currently priced at $53.55 \%$ of their originator price, i.e. a prescriptive pricing policy similar to countries such as France [12,13]. Equal medicine pricing (EMP) was implemented in April 2012 under the new principle of the "same medicine, same price [14]", i.e. internal reference pricing based on the molecule (ATC level 5) [15]. The previous pricing for generic medicines was 
established using a stepwise pricing scheme, i.e. the price was determined by the order of entrance into the market. Due to the EMP, the maximum price of generics has decreased to $53.55 \%$ from the previous $68 \%$ of the originator's price. Kwon et al. (2015) recently researched whether the aim of the EMP to introduce market competition among outpatient drugs by setting the same price for both generics and the originator and expecting generic manufacturers to further lower their prices to attract greater sales was achieved. However, despite the expectation that active price competition between generics and originators would occur and lead to substantial utilization of lower-cost generics, the market share of the originator medicine remained high with no price competition in reality [3]. During 2007-2013, a total of 10,071 generic products were listed, which amounts to an average annual listing of 1,439 generics per year [1]. This level of generic introduction is perhaps not surprising given potentially the high profitability for generics in Korea with prices of generics in a number of European countries as low as $2 \%$ to $10 \%$ of pre-patent loss originator prices [16-18].

\section{Pricing of line extension medicines}

For line extension medicines, the price is set using the following equation, whose components include the substances and price of the registered drug as well as a new drug's $(\mathrm{N})$ content [19]:

$P N=A X B$, if $\mathrm{N}$ has higher dose, $\mathrm{Eq}(1)$

$P N=A B$, if $\mathrm{N}$ has lower dose, $\mathrm{Eq}(2)$

where $\mathrm{A}$ is $53.55 \%$ of the price of the already listed drug, $\mathrm{B}=[($ High dose $) /($ Low dose $)-1] X 0.5+1$.

For example, when simvastatin $20 \mathrm{mg}$ has already been registered as costing $\$ 15$, and if simvastatin $10 \mathrm{mg}(\mathrm{N})$ is to be newly registered, the calculated price becomes $\$ 10(\$ 15 / \mathrm{B}, \mathrm{B}=1.5)$.

\section{Re-pricing measures}

Once listed, medicines can be subject to various and complicated re-pricing measures [19] as follows:

\section{Delisting}

Since 2007, listed medicines with no production and no claims history for two years are to be deleted from the reimbursement medicine list. Around 9,767 items were delisted during 2007-2013 [1].

\section{Drug list re-arrangement}

With the implementation of the PLS in 2007, the need to re-arrange the medicines that were already listed was raised because these had not been listed based on their cost-effectiveness. Consequently, a drug list re-organization project was introduced in which drugs listed before 2007 would be reappraised based on their current cost-effectiveness.

Registered drugs that were subsequently found not to be cost effective would be deleted from the reimbursement list. However, this project was contested by pharmaceutical companies, and contrary to its intention, the original plan was downgraded to a new method for drug price reduction in which the items were kept on the list if their prices were reduced over three years [20].

As a result, a reorganization of a total of 49 effective groups (12,825 items) was completed. Prices were reduced for 3,585 items, 546 items were delisted, and the costs saved on medicines expenditure was estimated at KRW 863.3 billion(USD 768 million) [21].

\section{Price cuts due to kickbacks}

Kickbacks between prescribers and manufacturers have been illegal but prevalent in Korea [22]. In order to eradicate this, the Korean government legislated dual punishments in November 2010. This law intended to punish both the givers and takers of kickbacks. For manufacturers, the sales of corresponding items would be suspended or they would be fined, and the prices of their products would be cut by the amount of the kickbacks when kickbacks were detected. For prescribers, the punishment included a potential prison sentence for a maximum of two years, a fine of KRW 30 million (USD 26,690) or less, and a suspension of their license without a fine for up to a year [23]. After 2011, there were kickbacks on 188 items and drug price reductions of up to 20\% [21]. However, even after the legislation for drug price reduction was introduced, kickbacks continued to occur, and as litigation for administrative suspension of MOHW's regulations on drug price reductions came forward, questions were raised regarding the legislation's effectiveness. Consequently, from July 2014 , kickbacks were strongly regulated, and to make the measures on medicines caught in violation more effective, drugs in violation ceased to receive insurance reimbursements. If they were caught 
two times or more, they would be deleted from the reimbursement list, known as the two strikes out system [24]. This measure is proving more effective.

\section{Actual transaction pricing (ATP)}

The ATP aims to reduce the gap between the reimbursement price and the actual transaction price. Since the NHIS reimburses medicine costs based on reimbursement prices announced monthly, reimbursement prices are adjusted to actual prices by investigating the actual prices for medicines through auditing samples [19]. The average price reduction rate was $0.94 \%$ in 2010 , estimated at KRW 15.4 billion(USD 13.7 million) in savings [1].

\section{Price cut for originator medicines after patent expiration}

As mentioned, once a patent expires and generics enter the market, the price of the originator medicines will be lowered to $53.55 \%$ (internal reference pricing). This is due to the EMP policy introduced in April 2012. During the 12-month grace period before its application, the originator medicine was to cut its price by $30 \%$, and, simultaneously, generics are to be priced at $85 \%$ of the originator's price $(70 \%$ * $85 \%=59.5 \%)$. After this period, the same molecules are to be priced at the same level, that is, $53.5 \%$ of the originator's price. Approximately $47 \%$ (6,506 products) of the total listed products were subject to price cuts [3]. The savings from these price cuts were estimated to be KRW 909 billion(USD 808.72 million) after six months of policy implementation [25].

\section{Price-volume agreement (PVA)}

PVAs are typically agreed during price negotiations for new medicines. If the actual volume of claims exceeds $30 \%$ in the first year in relation to the annually expected volume, the drug becomes subject to a price reduction according to the PVA regulations. At this time, the drug manufacturer negotiates the price reduction gap with the NHIS, and the maximum gap is set at 10\% [19]. After the negotiations were introduced in 2007, a total of 263 items went through price adjustments via the PVA. The average reduction was $6.6 \%$ [11].

\section{Others}

There is a mechanism for mediation for either an increase or decrease in drug pricing as per requests from the manufacturer. Mediation mechanisms are often applied for requests for drug price increases, and there are also additional price increase requests on products deemed unfit for further production due to profitability reasons. Whether the drug price adjustment application is appropriate or not is assessed by HIRA's DREC, and the price increase for drugs that pass the assessment is subsequently determined by drug price negotiation with the NHIS [19]. Between 2007 and 2012, there were applications for mediation on 142 items, and the final price was determined as an average of $78.9 \%$ of the price requested by the company [8].

\section{Discussion}

For Korea's health insurance system to be financially sustainable, regulating drug pricing is important. This has been justified by the fact that the proportion of drug costs was high in relation to total medical costs. As such, there are various regulations on drug prices, and this study confirmed that, essentially, different regulations were applied depending on the type of the drug. These have worked reasonably well in lowering medicine prices as well as removing obsolete products from the reimbursement list. For new drugs, the listing and pricing scheme has been well established since the DERP in 2007. Specifically, a recent evaluation stated that value for money of new drugs has been well reflected in reimbursement decisions, and has contributed to improving transparency and rationality [7]. In contrast, drug price negotiations confirmed the need for improvements in transparency and consistency [11].

Generic drugs, which comprise $97.2 \%$ of annually listed drugs, are automatically priced via a simple standard [1,14]. Despite the large number of items, further price reductions through price competition does not appear to function properly in Korea [3]. In addition, re-pricing mechanisms are complicated and would appear redundant. After the PLS, a rearrangement of pre-listed medicines on the basis of cost-effectiveness was needed. Unfortunately, this was considered a regrettable policy failure because the listing initiative was transformed into various repricing mechanisms rather than assessing whether to continue to reimburse medicines based on their cost-effectiveness, as undertaken in for instance Sweden when they re-assessed the value of reimbursed products in designated classes [17], or not. Diverse and complicated measures for drug price reduction mechanisms can cause manufacturer dissatisfaction when planning longer term. 
To increase policy receptiveness, there is a need to strive for health insurance sustainability through effective drug price policies. According to the government's recent measures for drug price reforms, there is a tendency to weaken pharmaceutical price regulations under the policy of fostering pharmaceutical industry development [26]. In other words, policies for easing drug price regulations are being proposed under the assumption that drug price regulation leads to profit reduction for pharmaceutical companies, thereby discouraging the development of new innovative medicines, which will cause difficulty in maintaining global competitiveness.

In the long run, there should be drug pricing policy management that involves follow-up of introduced policies before future policies are considered rather than implementing complex and inefficient pricing measures. This would reduce the dissatisfaction of pharmaceutical companies while maintaining the principle of value for money for new drugs and financial efficiency through price competition among generic drugs. Having said this, it is also acknowledged that gross profitability can be substantial for new medicines such as those for hepatitis $C$ where companies where charging up to US $\$ 84,000$ per course with cost of goods as low as US\$100 - 200 [27-29]. In addition, requested prices for new cancer medicines appear to currently bear little relation to research costs or to the health gain provided in terms of survival times [30], resulting in requests from clinicians to lower prices [31-33].

To help fund new medicines, as well as greater use of existing medicines with ageing populations, whilst still maintaining population coverage close to $100 \%$, there needs to be increasing use of generics at lower prices. Prices of generics in Europe can be as low as $2 \%$ to $10 \%$ of pre-patent loss prices through a variety of measures [15-18,34]. These include compulsory generic substitution, as well as encouraging high international non-proprietary name (INN) prescribing. In addition, regular review of generic prices and only funding the cheapest generics [15-18,34]. There appears considerable room for further price reductions of generic medicines in Korea, building on existing measures. These measures do not need to be complex. This along with initiatives to increase the prescribing of generics versus originators, as well as patented products in a class without compromising care, can achieve considerable savings in Korea.. In addition, re-focusing efforts on delisting or disinvestment of medicines no longer providing value. This builds on earlier measures in Korea before there was a re-focus on pricing as well as successful examples in other countries [35].These are considerations for the future.

\section{Compliance with Ethical Standards}

This study is self-funded. Hye-Young Kwon and Brian Godman declared no conflicts of interest. The authors would like to express their deepest appreciation to Prof. Bong-min Yang from Seoul National University for his advice when developing the draft manuscript.

\section{Author Contributions}

HYK jointly conceived the study with BG. HYK designed and collected data. HYK and BG prepared the first and successive manuscripts.

\section{References}

[1] Ministry of Health and Welfare. Statistics for national health insurance and health policy. Seoul 2 014.

[2] Ministry of Health and Welfare. Drug expenditure rationalization plan (DERP). Press release May 03, 2006. Available at: http://www.mw.go.kr/front/al/sal0301vw.jsp?PAR MENU ID=04\&MENU I $\mathrm{D}=0403 \&$ CONT SEQ $=37687$ \&page $=1 \&$ SEARCHKEY $=$ TITLE\&SEARCHVALUE. [Accessed May 17, 2016].

[3] Kwon HY, Kim HM, Godman B., Reich M. The impact of South Korea's new drug-pricing policy o n market competition among outpatient drugs. Expert Rev Pharmacoecon Outcomes Res. 2015; 15(6):1007-14

[4] National Health Insurance Service. History of the Korean national health insurance. Available at http://www.nhis.or.kr/menu/retriveMenuSet.xx?menuld=B2160 (accessed on 28 July 2016) [Acce ssed June 17, 2016].

[5] Jeong HS, Sin JW. Debates on the national health insurance coverage and international compari son. HIRA policy brief 2011; March:17-27. 
[6] OECD. Pharmaceutical expenditure. Health: Key tables from OECD, No. 7. DOI: 10.1787/pharm exptable-2014-1-en [Last accessed June 17, 2016].

[7] Bae EY, Hong JM, Kwon HY, et al. Eight-year experience of using HTA in drug reimbursement: South Korea. Health Policy 2016; 120(6):612-20.

[8] Ministry of Health and Welfare. Enforcement regulations of national health insurance. Raw article 10-2. Application of drug reimbursement decision no. 404; June 03, 2014.

[9] Adamski J, Godman B, Ofierska-Sujkowska G, Osinska B, Herholz H, Wendykowska K, et al. Risk sharing arrangements for pharmaceuticals: potential considerations and recommendations for European payers. BMC health services research. 2010;10:153.

[10] Ferrario A, Kanavos P. Managed entry agreements for pharmaceuticals: The European experience: LSE; 2013 [cited http://ec.europa.eu/enterprise/sectors/healthcare/files/docs/mea report en.pdf].

[11] Kim JH, Lee TJ, Kim Eugene, Bae H, Kim SJ. Strengthening transparency of drug pricing negotia tion. Seoul National University and NHIS. August 2013.

[12] Godman B, Shrank W, Wettermark B, Andersen M, Bishop I, Burkhardt T et al. Use of Generics-A Critical Cost Containment Measure for All Healthcare Professionals in Europe. Pharmaceuticals 2010;3(8):2470-94.

[13] Sermet C, Andrieu V, Godman B, Van Ganse E, Haycox A, Reynier JP. Ongoing pharmaceutical reforms in France: implications for key stakeholder groups. Applied health economics and health policy. 2010;8(1):7-24.

[14] Ministry of Health and Welfare. New drug price policy will be implemented in April 2012. Press rel ease 2012. Available from: http://www.mw.go.kr/front new/al/sal0301vw.jsp?PAR MENU ID=04 \&MENU ID=0403\&page $=183 \& C O N T$ SEQ $=267283$

[15] Simoens S. A review of generic medicine pricing in Europe. GaBI. 2012;1(1):8-12.

[16] Godman B, Bishop I, Finlayson AE, Campbell S, Kwon HY, Bennie M. Reforms and initiatives in Scotland in recent years to encourage the prescribing of generic drugs, their influence and implications for other countries. Expert review of pharmacoeconomics \& outcomes research. 2013;13(4):469-82.

[17] Godman B, Wettermark B, Hoffmann M, Andersson K, Haycox A, Gustafsson LL. Multifaceted national and regional drug reforms and initiatives in ambulatory care in Sweden: global relevance. Expert review of pharmacoeconomics \& outcomes research. 2009;9(1):65-83.

[18] Woerkom M, Piepenbrink H, Godman B, Metz J, Campbell S, Bennie M, et al. Ongoing measures to enhance the efficiency of prescribing of proton pump inhibitors and statins in The Netherlands: influence and future implications. Journal of comparative effectiveness research. 2012;1(6):527-38.

[19] Ministry of Health and Welfare. Pricing and re-pricing standards for reimbursable pharmaceutical s. Notification No. 2015-80. May 29, 2015.

[20] Lee HY, Kim JH. Delisting policy reform in South Korea: Failed or policy change? Value Health 2 012; 15(1):204-212.

[21] National Health Insurance Service. Handbook of drug expenditure management policy 2014.

[22] Yu SY, Yang BM, Kim JH. New anti-rebate legislation in South Korea. Appl Health Econ Health P olicy. August 2013; 11(4):311-8.

[23] Law of Pharmaceutical Affairs. Article 76: Marketing approval cancellation and suspension of bus iness. No.25583. September 01, 2014.

[24] Presidential Decree of National Health Insurance. Article 18-2: Suspension and exclusion of drug 
reimbursement service. No.25583. August 20, 2014.

[25] Ministry of Health and Welfare (MOHW). Six months after the massive price cuts, drug expenditu re savings of 909 billion Korean won. Press Release February 07, 2013 [Accessed May 17, 2016 ].

[26] Ministry of Health and Welfare. Certification of innovative pharmaceutical companies and pricing policy: Follow-up of the $10^{\text {th }}$ trade investment promotion. Press release July 07, 2016.

[27] Phelan M, Cook C. A treatment revolution for those who can afford it? Hepatitis C treatment: new medications, profits and patients. BMC infectious diseases. 2014;14 Suppl 6:S5.

[28] Brennan T, Shrank W. New expensive treatments for hepatitis $C$ infection. JAMA : the journal of $t$ he American Medical Association. 2014;312(6):593-4.

[29] de Bruijn W, Ibanez C, Frisk P, Bak Pedersen H, Alkan A, Vella Bonanno P, et al. Introduction an d Utilization of High Priced HCV Medicines across Europe; Implications for the Future. Frontiers i n pharmacology. 2016;7:197.

[30] Godman B, Malmstrom RE, Diogene E, Gray A, Jayathissa S, Timoney A, et al. Are new models needed to optimize the utilization of new medicines to sustain healthcare systems? Expert review of clinical pharmacology. 2015;8(1):77-94.

[31] Experts in Chronic Myeloid Leukemia (2013), The price of drugs for chronic myeloid leukemia (C $\mathrm{ML}$ ) is a reflection of the unsustainable prices of cancer drugs: from the perspective of a large gr oup of CML experts. Blood. 2013;121(22):4439-42.14.

[32] Kantarjian HM, Fojo T, Mathisen M, Zwelling LA. Cancer drugs in the United States: Justum Preti um--the just price. Journal of clinical oncology. 2013;31(28):3600-4.

[33] Tefferi A, Kantarjian H, Rajkumar SV, Baker LH, Abkowitz JL, Adamson JW, et al. In Support of a Patient-Driven Initiative and Petition to Lower the High Price of Cancer Drugs. Mayo Clinic proc eedings Mayo Clinic. 2015.

[34] Godman B, Abuelkhair M, Vitry A, Abdu S, Bennie M, Bishop I et al. Payers endorse generics to enhance prescribing efficiency; impact and future implications, a case history approach. GaBI.

2012;1(2):69-83

[35] Parkinson B, Sermet C, Clement F, Crausaz S, Godman B, Garner S, et al. Disinvestment and Value-Based Purchasing Strategies for Pharmaceuticals: An International Review.

PharmacoEconomics. 2015;33(9):905-24 